\title{
Certifications in construction: a case study comparing LEED and HQE
}

\author{
E. Vazquez ${ }^{1}$, M. Miguez ${ }^{2}$, L. Alves ${ }^{3}$, J. Valente $^{3}$ \& G. Rossi ${ }^{4}$ \\ ${ }^{1}$ Department of Civil Construction, Urban Engineering Program, \\ Federal University of Rio de Janeiro, UFRJ, Brazil \\ ${ }^{2}$ Department of Transportation Engineering, Urban Engineering \\ Program, Federal University of Rio de Janeiro, UFRJ, Brazil \\ ${ }^{3}$ Department of Civil Construction, Federal University of Rio de Janeiro, \\ UFRJ, Brazil \\ ${ }^{4}$ Department of Graphics, Urban Engineering Program, \\ Federal University of Rio de Janeiro, UFRJ, Brazil
}

\begin{abstract}
Proposal: This paper presents concepts of sustainability embedded in environmental certifications applied to building construction. The article addresses the importance of certification and the benefits to the environment coming from its deployment. Building constructions consume many materials, emit many gases, and use a lot of energy and water, what point to the extreme importance of developing processes that aim to conserve natural resources, using them optimally. It is necessary to identify actions needed to integrate all the steps involved in the project life cycle, including entrepreneurs, developers, builders, manufacturers, managers of enterprises, users and society. Among these reasons, arises the certification process of the project, which helps minimizing the environmental impacts using natural resources in a more conscious way. This paper aims to present the concepts of an environmental certification focused on construction, compare two of these systems: LEED (Leadership in Energy Environmental Design) and HQE (Haute Qualité Environnementale), its application methodologies application methodologies, the phases in which they apply during the life cycle of an enterprise, and their benefits. Research Structure / Approaches: The article is structured in three parts: a brief review on this topic historic evolution; a description of the main features of the existing certification procedures; and case studies covering a LEED certified building and
\end{abstract}


another with HQE certification. Contributions: The sustainable construction is based on actions that enable the building construction to encounter or create solutions for ecological problems, using technology, selecting the materials and their suppliers, creating buildings that meet the needs of their users and, also, the environment.

Keywords: sustainability, environmental certifications, building construction, certification LEED, Certification HQE.

\section{Introduction}

The Industrial Revolution began in the eighteenth century and was marked by the creation of the machine, locomotives and steam trains, exploration of coal, iron and steel. England was the pioneer in this area due to large reserves of coal and also iron ore (Gottfried [1]).

Humanity was concerned solely with production and consumption, overestimating the planet's capacity to assimilate the exploitation of natural resources, which brought consequences that eventually emerged with increasing noise pollution, environmental degradation, rural exodus and the uncontrolled growth in cities that still happens up to the present today.

In this timeline, the sustainability issue was relegated to low priority, taking shape in the mid-nineteenth century. Humanity's concern with planet development begins in the 60 's, when the debates on environmental degradation started.

Civilian buildings consume many materials, emit many gases, use lots of energy and water, making a new vision extremely important to conserve the natural resources, using them optimally, taking this awareness to all parties involved in the process (from the builder up to the user) (Krygiel and Nies [2]).

Amid these reasons, arises the environmental certification process of the venture, which collaborate minimizing environmental impacts, using, in a more conscious way, natural resources resulting in many benefits.

In the Brazilian market there are two main systems of environmental certification of buildings, the LEED (Leadership in Energy Environmental Design) developed by the U.S. in 1991 and the HQE (Haute Qualité Environnementale) developed by France in 2002.

\section{Methodology}

The subject matter was developed through a comparative case study between the two certification processes, LEED and HQE, in order to identify the best practices, differences and similarities seeking a critical analysis to integrate the concepts of sustainable construction. The preparation of the article was based on literature research, articles and magazines, creating a comparative of efficient solutions for sustainability. 


\section{Sustainable construction}

Sustainable construction is developed based on actions that enable construction to encounter and create solutions to environmental problems using technology, selecting the materials and their suppliers, creating constructions that meet the needs of their users and the environment.

To have a sustainable building is important to evaluate the site of the construction, planning every step in order to reduce the aggression to the environment before, during and after the construction. The foundation of these buildings is to study and use the constructive elements that do not harm the environment, using recyclable materials that save water, with energy efficiency, minimizing air pollution and providing better comfort for its users.

It is important not only to build sustainably, but also to prove that the building actually follows these assumptions, especially after occupation. Sustainable constructions generate fewer environmental impacts covering all stages of the building's life cycle, from the conception of the product and design, through the process of construction and use of buildings, reaching the stage of demolition. Being of great relevance the understanding of this cycle, to make decisions in advance and minimize the future effects as described in table 1 (Yudelson [3]).

Table 1: Building's life cycle phases.

\begin{tabular}{|c|l|}
\hline PLANNING & $\begin{array}{l}\text { Beginning of the life cycle of a building. Financial } \\
\text { feasibility studies, project design and specifications } \\
\text { and the development of constructive activities are } \\
\text { conducted. }\end{array}$ \\
\hline IMPLANTATION & $\begin{array}{l}\text { Phase of construction of the building, putting into } \\
\text { practice the projects developed. }\end{array}$ \\
\hline USE & Phase contemplated by the building's use. \\
\hline MAINTENANCE & $\begin{array}{l}\text { Phase where the need arises for replacement of } \\
\text { certain elements, maintenance of equipment and } \\
\text { systems, correction of any failure of performance. }\end{array}$ \\
\hline DEMOLITION & Phase when the product is no longer used. \\
\hline
\end{tabular}

In each phase of the lifecycle of the building there are many benefits that focusing on sustainability can bring to the environment. Designers in addition to understanding this importance need to insert these constraints in the design phase on activities that can interact with the environment, from the specification of materials to the indoor air quality during the occupation of the buildings, passing through the location of the enterprise, adopted lighting systems, air conditioning and water heating.

\section{Certification in construction}

Many meetings and conferences that have been held for years, tried to get the environmental quality, by new technologies, with help from organizations and 
creating new business models. Thus appearing tools aimed at environmental and social responsibility, such as certification in construction. The table 2 presents the history of certifying agencies worldwide.

Table 2: $\quad$ History of certification.

\begin{tabular}{|c|c|c|}
\hline Year & Country & Certification \\
\hline 1990 & England & BREEAM \\
\hline 1999 & USA & LEED \\
\hline 2002 & Australia & Green Star \\
\hline 2002 & France & $H Q E$ \\
\hline 2003 & USA & Cal-Arch \\
\hline 2004 & Australia & Nabers \\
\hline 2004 & USA & Energy Star \\
\hline
\end{tabular}

The certification in construction is an important tool that establishes a process for managing the impacts of construction on the environment, consolidating the responsibilities of all parties involved as business and environmental control agencies.

As basis for this study were used two certification systems, the LEED (Leadership in Energy Environmental Design) process, which is done by the Green Building Council Brazil, with basis on American criteria and the HQE (Haute Qualité Environnementale) process or AQUA (Alta Qualidade Ambiental) being conducted by Foundation Vanzolini with the basis on Brazilian criteria.

\subsection{Certification objectives}

The purpose of certification is to promote an awareness of all involved in the process, from the design phase through construction, until the user, incorporating solutions that will enable a reduction in the use of natural resources, promoting comfort and quality to its users.

A greater investment initially is presented, but has lower operating costs, valuing the property, being healthier for its users, conserving water and energy, and reducing gas emissions.

The organizations that carry out the certification provide standards and instructions for the best production of the project and evaluate if they are being followed. Incremental changes are made rather than radical ones, and methods of design and construction are used for the establishment of enterprises with high performance. The organization has a label that proves the product sustainable.

\subsection{Benefits of certification}

The square footage of the property, the number of rooms, location and conditions for shopping, is information presented in many ads for sales of the enterprises. Some companies are including on the ads the labels of "green buildings". A way to confirm if the property is in line with the propaganda of 
"green building" is whether it has any type of certification provided by some organization or its representative. At the time of purchase, to make the best choice considering the price and quality of the property is necessary to evaluate how the building was designed, not to encourage the aggression to the environment and health of its users.

The benefits brought by the certification of a building are visible in the long term. The largest impacts seek to reduce consumption of water and energy, and this factor will not always contribute at the time of purchase due to high initial cost.

Certifications are a means of valuing the enterprise in the market and there is no single standard of reference. What can occur is that a certain type of certification may not be suitable for all projects, due to its own concept.

The company is recognized in the market as environmentally friendly by linking the brand to the product, with the potential to reach new markets, reducing production costs and attracting new investment, making it easier to obtain financing.

\subsection{LEED Certification}

Developed by USGBC, which is a nonprofit organization with a focus on sustainability of buildings and real estate, in the United States since 1991, the system was developed for guidance and certification of sustainable constructions, internationally recognized. It confirms that the buildings were designed and constructed through strategies that aim to improve performance in terms of energy, water, reduction of $\mathrm{CO} 2$ emissions, better indoor quality, managing the use of natural resources and minimizing environmental impacts.

LEED is a voluntary system that can be applied to any type of construction and at any stage of the life cycle of the enterprise. This certification quantifies the level of environmental protection that an enterprise can redeem. In Brazil, it was implemented by GBC Brazil, in January 2008.

It is necessary to meet some requirements that are variable and depend on the category of certification, to obtain the score. The minimum requirements to be met at the stage of the project can earn points for certification and if not met, the project cannot be certified.

Each category of performance sums a score that defines the type of certification that will be appropriate to the enterprise. The total score determines which level of certification the project is included, which can be: certified, silver, gold or platinum.

\subsection{HQE Certification}

After the conference held in Rio, ECO 92, arose reflections in many countries. As a result of this conference, in 2002, the HQE (Haute Qualité Environnementale) was created, which is a process based on performance benchmarks established in the Centre Scientifique et Technique du Bâtiment (CSTB), created in 1947, in France. 
In Brazil, it is also known as process AQUA (Alta Qualidade Ambiental), adapted from the original model of the $H Q E$ for the Brazilian version in 2007. It was implanted by the Vanzolini Foundation, a private institution non-profit organization, formed and maintained by professors at USP (Universidade de São Paulo) since 1967. The process certifies that the $A Q U A$ development is in accordance with the requirements through independent audits.

The $H Q E$ is a project management process in order to obtain the environmental quality of a project construction or rehabilitation, accepting solutions that bring economies to the project.

This system has a technical reference, which is adapted to Brazil that has as characteristic to adapt to the climate of the region in which it will be deployed demanding performance results. During the process, all the Brazilian prevailing Standards are used, which are quoted in the technical reference material produced by the Vanzolini Foundation. If there is absence of some Brazilian standards, international standards may be used.

The process is structured into two instruments to assess the performance required, the enterprise management system (EMS) and environmental quality of the building (EQB).

This system is based on performance, therefore there is no score. Three performance levels are considered: good, excellent and superior. Certification requires at least three categories in excellent level, four in superior and seven in good performance level, totaling fourteen items, which will be based on audit findings, an environmental profile of an enterprise.

\subsection{LEED versus $H Q E$}

The certification systems presented have specific characteristics and requirements each. By applying one of them in an enterprise, from the initial phase (design), it is expected that, compared to traditional buildings, it has a superior performance. The following tables are presented with the main features of both types of certification: LEED and $H Q E$.

Table 2 presents a comparison for the organization of each of these systems, in which are evaluated the scope, method of application, categories evaluated and results.

Table 3: $\quad$ Comparison of organization of systems.

\begin{tabular}{|c|c|c|c|}
\hline Aspects & $\begin{array}{c}\text { Method of } \\
\text { Application }\end{array}$ & Categories evaluated & Results \\
\hline LEED & $\begin{array}{c}\text { Attendance of } \\
\text { mandatory and } \\
\text { qualifier items. }\end{array}$ & $\begin{array}{c}\text { Sustainable site, energy, water } \\
\text { efficiency, materials and } \\
\text { resources, indoor quality, } \\
\text { innovation and design process. }\end{array}$ & $\begin{array}{c}\text { Four levels: certified, } \\
\text { silver, gold and } \\
\text { platinum. By total score } \\
\text { obtained. }\end{array}$ \\
\hline$H Q E$ & $\begin{array}{c}\text { Attendance of an } \\
\text { environmental } \\
\text { profile. Building } \\
\text { certificated or not. }\end{array}$ & $\begin{array}{c}\text { Eco-construction, } \\
\text { Ecomanagement, } \\
\text { Comfort and health. }\end{array}$ & $\begin{array}{c}\text { The certification is } \\
\text { obtained through } \\
\text { attendance to the profile } \\
\text { of environmental } \\
\text { performance chosen. }\end{array}$ \\
\hline
\end{tabular}


Table 4: $\quad$ Characteristics of different methodologies.

\begin{tabular}{|c|c|c|}
\hline CHARACTERISTIC & $H Q E$ & LEED \\
\hline Model and network & $\begin{array}{c}\text { Global network with local criteria, } \\
\text { based on the French model }\end{array}$ & $\begin{array}{c}\text { North American model, with } \\
\text { global representations }\end{array}$ \\
\hline $\begin{array}{c}\text { Adequacy of criteria to } \\
\text { Brazil }\end{array}$ & Yes & No \\
\hline Stages of evaluation & $\begin{array}{l}\text { Programming, conception e } \\
\text { implementation }\end{array}$ & Conception \\
\hline $\begin{array}{l}\text { Typology of current } \\
\text { buildings }\end{array}$ & Office buildings, schools and hotels & $\begin{array}{c}\text { Core, frontage, office } \\
\text { buildings, commercial, } \\
\text { residential, lots, neighborhoods, } \\
\text { hospitals, shops, schools }\end{array}$ \\
\hline Scope & Environment, comfort and health & $\begin{array}{c}\text { Environment, comfort and } \\
\text { health }\end{array}$ \\
\hline Expression of results & $\begin{array}{c}\text { Performance profile in different } \\
\text { themes }\end{array}$ & Overall performance level \\
\hline
\end{tabular}

These systems have different characteristics in methodology. It is necessary to examine which fits best for the venture that will be certified, illustrated by table 3 (Téchne [4]).

These systems have common concerns, such as saving water and energy usage, reducing emission of carbon gases, deployment in the territory, internal comfort and waste management. In the U.S. the biggest concern is the issue of energy therefore LEED corresponds to energetic leadership.

The weight percentage of each item is showed in Figure 1, by each evaluation methodologies. As noticed, LEED is not a uniform system, where a higher percentage in energy efficiency is found, focusing more on some points and less on others. Otherwise, the system $H Q E$ presents uniformity in the categories, considering the same importance to all items (Melhado [5]).

\begin{tabular}{|c|c|}
\hline \multirow{2}{*}{$3 \%$} & $12,50 \%$ \\
\hline $18,80 \%$ & $12,50 \%$ \\
\hline $21,70 \%$ & $12,50 \%$ \\
\hline $7,30 \%$ & $12,50 \%$ \\
\hline $10,10 \%$ & $12,50 \%$ \\
\hline $18,80 \%$ & $12,50 \%$ \\
\hline $20,30 \%$ & $12,50 \%$ \\
\hline LEED & $12,50 \%$ \\
\hline
\end{tabular}

Management development

Implantation Quality

Materials consumption

Construction site management

Rationalization of water use

Energy efficientand pollution emissions

Quality of indoor environmentand health of occupants

Operation and maintenance

Design Innovations

Figure 1: Comparison of the weight of the different themes. 


\section{Case study: certification LEED and $H Q E$}

The case study presents the innovations that were made in the implementation of the process of environmental certification LEED and $H Q E$ in different projects.

For the LEED certification system, the object of study was the Ventura Corporate Towers office building which is an enterprise composed of two towers with 36 floors, five basement floors and a garage building of five floors. It is the first certified enterprise in the gold category in Rio de Janeiro. The commercial building, Ventura Corporate Towers, was framed in the category Core \& Shell which has a total of 61 points and the project received 35 points, reaching the gold level of certification.

For the $H Q E$ certification system, the object of study was the first certification in this system in Brazil, also a commercial building. The Leroy Merlin chose the AQUA certification because of its easiness to adapt to the Brazilian needs, developing its criteria that assess the environmental management of construction and architecture. It aimed for the quality of life for employees and customers, saving energy and water, waste disposal and maintenance, contributing to socioeconomic and environmental development of the region.

\subsection{Certification LEED - Ventura Corporate Towers}

Hereafter are the strategies employed, according to the concepts of sustainability required by LEED: Sustainability of space, energy efficiency, rationalization of water use, sustainable materials and indoor environmental quality in the construction site (USGBC [6]).

In the phase of construction, aiming the sustainability of the space, there was planning to ensure that precautions have been taken to avoid environmental impact, and problems with neighbors and employees. To preserve the local soil and prevent contamination with chemicals, products with low volatile organic compounds were not accepted in the construction site.

Relating to energy efficiency, the building has a glass frontage, which requires high energy consumption in the use of air conditioning. As a solution to reduce energy consumption, laminated glass $10 \mathrm{~mm}$ thick were used with special reflective, which have low thermal transmission of heat and provide natural lighting, thereby reducing the consumption of air conditioning. For energy management sensing light was also used, and the use of reactors and high-tech lamps that consume less energy.

In efficiency in water use, a system was created for retention and reuse of rainwater, which will be captured around the perimeter and will be conducted to a tank for reuse, where it will be pumped into the air conditioning system. Water saving devices were also used such as timers faucets, flush valves with flow control, and presence sensors in urinals.

The materials used in construction, such as steel, concrete and grout are made from $20 \%$ to $30 \%$ recycled materials and the companies that supply them were located up to $800 \mathrm{~km}$ of the enterprise by reducing the emission of $\mathrm{CO}_{2}$ into the 
atmosphere. The wood used in construction was certified, ensuring the legality of the product. The trash generated in the phase of construction was collected, separated and received appropriate destination for each type of waste, being sent to specific recycling companies, e.g., such as drywall.

To cover the quality of the internal environment, prestressed ribbed slabs were used without intermediate pillars to ensure an interspace of 14 meters and thus allow for flexibility to internal spaces. Also, with the glass frontage and the use of tight frames that reduce air penetration, this system prevents the entry of pollutants such as carbon dioxide into the commercial rooms, ensuring good indoor air quality. To maintain air quality, smoking is prohibited inside the building, being only possible to smoke within a distance of $8 \mathrm{~km}$ of any entrance.

A summary of the main strategies adopted to meet the requirements of LEED certification is presented in figure 2 .

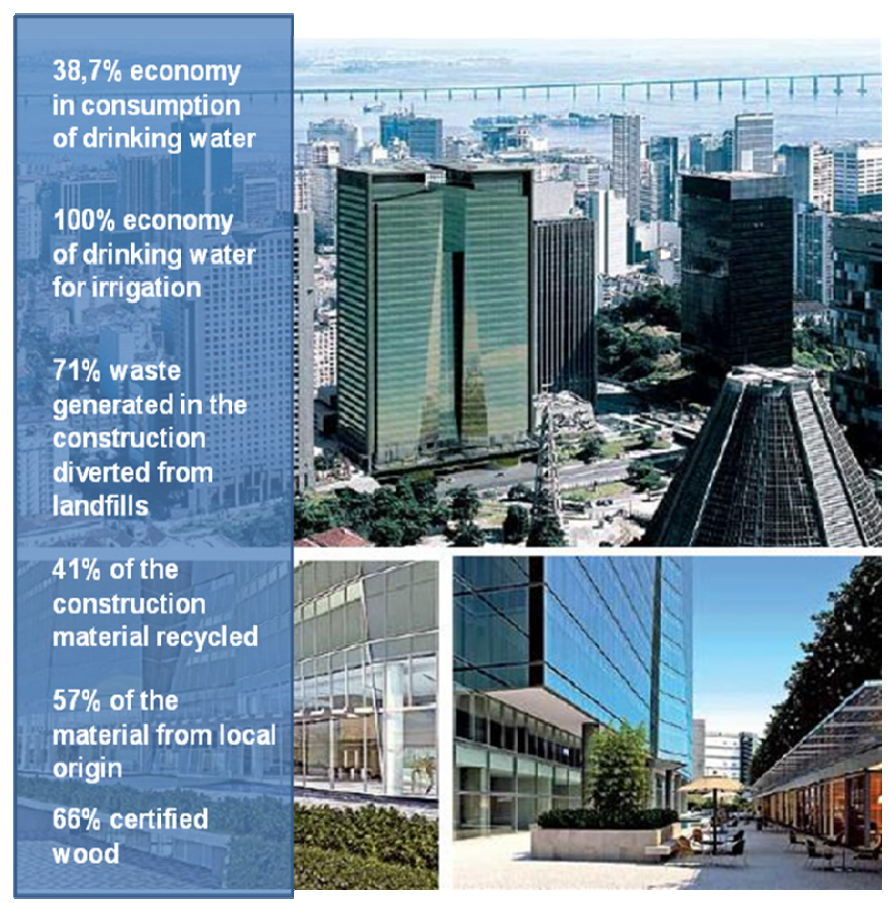

Figure 2: $\quad$ Requirements strategy LEED.

\subsection{Certification $H Q E$ - Leroy Merlin}

Hereafter are the strategies employed, according to the concepts of sustainability required by the $H Q E$ certification: project design, completion of the construction, through an Enterprise Management System (EMS) to meet the performance criteria of the Environmental Quality of Building (EQB) (Vanzolini [7]). 
The construction site was designed to cause little environmental impact. Through the separation of waste, woods, metals, stones and cement bags were sent for recycling. This way, the demolition stones became pavement and access of the store after recycling.

Eco-efficient materials were used, such as water-based paint that does not affect nature and discharge valve with dual flow that releases water with more or less intensity. Special urinals that use no water were also used, bringing technology and hygiene.

A project was developed to reduce the risk of flooding in the region and not waste the rain water, preserving groundwater. In addition, a reservoir of 150,000 liters was built below the parking lot, the rain water captation systems, storage and distribution. The water abstracted is used for discharge of toilets, watering gardens, outdoor and indoor cleaning. This system allows a saving of $50 \%$ of water.

In the energy scope, photovoltaic panels were installed, besides reflectors, and spots on the frontage with LEDs, which have low energy consumption. Special air conditioners were used that automatically adjust indoor temperature. These initiatives allow a saving of $17 \%$ of energy.

The floor inside the building was done in polished concrete, for easy cleaning, requiring only a damp cloth, and no use of chemicals.

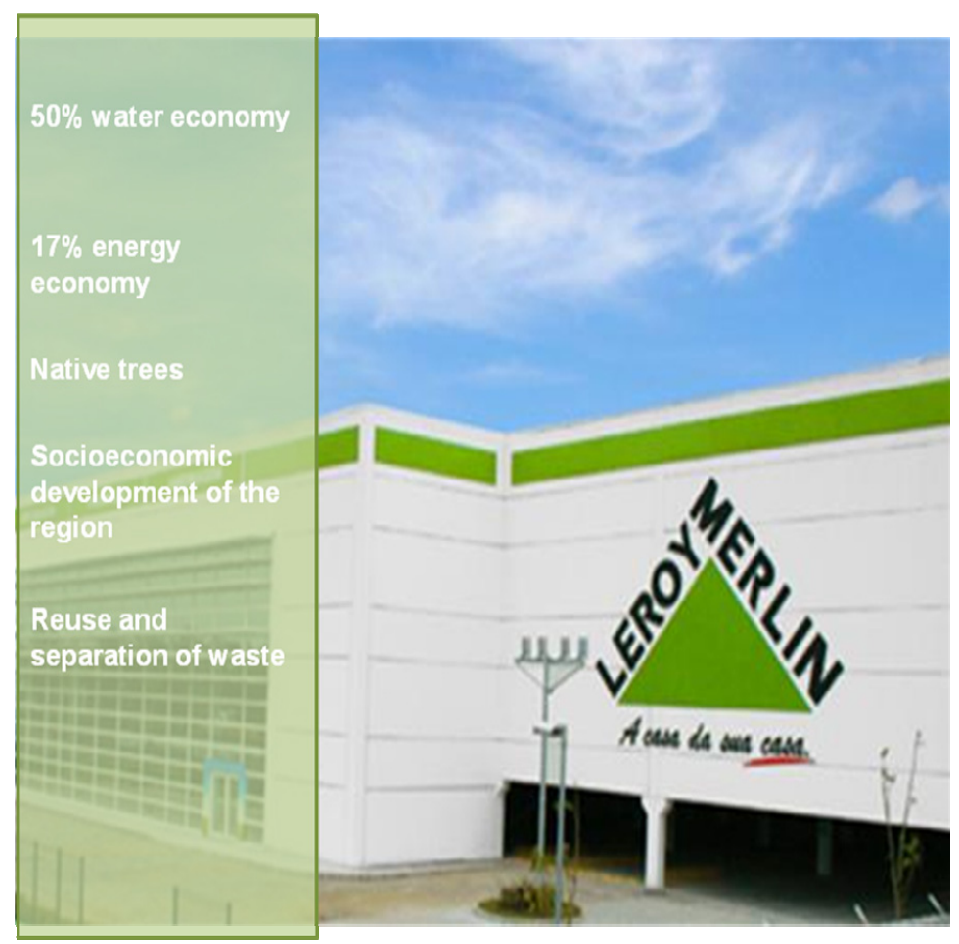

Figure 3: Requirements strategy $H Q E$. 
The front of the store was turned to the west but this problem was solved by using materials for protection against heat, solutions provided in the phases of program and design. The frontage of the store is composed of glass and louvers that prevent heating inside the store and allow natural lighting, reducing costs on air conditioning and therefore energy.

At the entrance of the store, crawlers were adopted to provide access to disabled and facilitate, to the users, the exit of shopping carts from the store to the parking lot.

The landscaping of the store is composed by planted trees, as paubrasil and other species that attract birds, making the environment a pleasant place for employees and visitors while preserving the region's fauna. Inside the store is installed an "Ecometer" that tells all the savings made in the store in real time. In the store parking lot exist several posters that have information about the innovations made during the stage of construction, as the case of reuse of rainwater done in the shop, passing on to their customers their commitment to environmental responsibility. The store displays "eco sustainable" products for its customers, stimulating the market with the vision on environmental and economical responsibility.

A summary of the main strategies adopted to meet the requirements of $H Q E$ certification is presented in figure 3 (Merlin [8]).

\section{Final considerations}

During this work it was possible to observe that the systems presented are viable, bringing environmental and economic benefits and have similarities among themselves in relation to environmental responsibility, despite of having different methodologies.

It was noted throughout this paper that LEED is a certification system aimed at the U.S. being inflexible in some areas, especially in categories where the score for enterprise punctuates certain item or not, being fully returned to the project and not for performance the building. With this, ends up creating some obstacles in certain situations where some concepts are required, since each city has its own characteristics and problems.

The $H Q E$ is the opposite, it fits to the reality of the location, being more flexible and allowing choices in favor of better performance. Each project has a potential of performance and economy, and the project can justify their decisions to change due to its location, ventilation, lighting, etc.

Both systems of certification bring economic benefits to their users, besides awakening awareness on the environment. It is important that constructors and companies pay attention to these systems, because being used on a larger scale, will bring greater benefits to entrepreneurs, to users and will also be contributing to the environment.

The certification in construction is a big step to be adopted and counts with the collaboration of professionals such as designers and builders, as well as the users, having as purpose a construction that has less impact on the environment, using new resources and reuse of materials. 
The current range of these systems at the national level is still small compared with the volume of construction in progress, but these organizations are taking important steps, contributing to a better quality of life, preserving the environment with ecological awareness and social responsibility.

\section{References}

[1] David Gottfried, "Green Building Design, Construction and operations", 1996

[2] Eddy Krygiel \& Bradley Nies, "Green Bim", 2008

[3] Jerry Yudelson, "Green Building A_to_Z", 2007

[4] http://www.revistatechne.com.br/engenharia-civil/133/imprime77962.asp, in October2009

[5] http://www.asec.com.br/v3/docs/Doc_Encontro09_AnaMelhado.pdf, in September 2009

[6] www.usgbc.org, in July 2009

[7] www.vanzolini.org.br, in September 2009

[8] www.leroymerlin.com.br, in November 2009 